\title{
Erratum to: Three-and-a-Half-Factor Model? The Genetic and Environmental Structure of the CBCL/6-18 Internalizing Grouping
}

\author{
Sanja Franić $\cdot$ Conor V. Dolan · Denny Borsboom •
}

Catherina E. M. van Beijsterveldt •

Dorret I. Boomsma

Published online: 24 December 2013

(C) Springer Science+Business Media New York 2013

\section{Erratum to: Behav Genet}

DOI 10.1007/s10519-013-9628-4

The Acknowledgement was inadvertently omitted from the original publication of this article. The text should read as given below:

Acknowledgments This work was funded by the European Research Council Grant 230374 to D.I. Boomsma.

The online version of the original article can be found under doi:10.1007/s10519-013-9628-4.

S. Franić $(\varangle)$. C. V. Dolan · C. E. M. van Beijsterveldt . D. I. Boomsma

Department of Biological Psychology, Faculty of Psychology and Education, VU University Amsterdam, Van der

Boechorststraat 1, 1081 BT Amsterdam, The Netherlands

e-mail: s.franic@vu.nl

D. Borsboom

Department of Psychological Methods, University of

Amsterdam, Amsterdam, The Netherlands 